\title{
PROBLEM OF SUPER-STRONG MAGNETIC FIELDS ON THE SUN: BRIEF CHRONOLOGY AND NEW OBSERVATIONAL DATA
}

\author{
V.G. Lozitsky ${ }^{1}$, V.B. Yurchyshyn ${ }^{2}$, K. $\mathrm{Ahn}^{2}$, H. Wang ${ }^{2}$, N.I. Lozitska ${ }^{1}$ \\ ${ }^{1}$ Astronomical Observatory of the Taras Shevchenko National University \\ of Kyiv, Kyiv, Ukraine,lozitsky@observ.univ.kiev.ua,nloz@observ.univ.kiev.ua \\ ${ }^{2}$ Big Bear Solar Observatory, New Jersey Institute of Technology, \\ Big Bear City, USA, vayur@bbso.njit.edu
}

\begin{abstract}
In this study we present the old and new observational data concerning the problem of extreme magnetic fields $(\geq 5 \mathrm{kG})$ in the Sun's atmosphere. We emphasize that the upper limit of the intensity of the magnetic field in the solar atmosphere is unknown to date. Severny (1957) heuristically suggested that the magnetic fields in the sunspots could reach $50 \mathrm{kG}$. As for the observational data, at least three arguments in favor of the magnetic fields of the order of $\leq 10^{4} \mathrm{G}$ can be specified: (1) the dependence of the measured magnetic field on the factor $g_{\text {eff }} \lambda^{2}$ of magnetosensitive lines (Gopasyuk et al., 1973; Lozitsky, 1980), (2) local extremums in splitting of bisectors in the profiles $I \pm V$ for lines with different Lande factors (Lozitsky, 1980; 2015) and (3) the reliable splitting of emission peaks in Fe I lines with very low Lande factors, about 0.01 , in the spectra of powerful solar flares (Lozitsky, 1993; 1998). Theoretically, superstrong fields should have gigantic magnetic pressure and can exist only with a specific topology of field lines, apparently of a force-free type (Soloviev and Lozitsky, 1986). To further develop this problem, we are analyzing new observational data obtained with the NIRIS spectropolarimeter of the largest GST solar telescope of the Big Bear Solar Observatory (BBSO). Our observations relate to the active region NOAA 12673, which was the most flare-productive in the $24^{\text {th }}$ cycle. Stokes-metric measurements are made in the FeI $15648.5 \AA$ line with a signal-to-noise ratio of about $10^{-4}$. In this active region, superstrong magnetic field of $5.57 \mathrm{kG}$ was discovered recently by Wang et al. (2018). An additional study of about 70 different places in this active region suggested that there were two types of places that can be conventionally called "typical" and "peculiar". In "typical" areas, the magnitude of the magnetic field in general is the greater, the less the intensity in the spectral continuum, and the maximum field here does not exceed $4 \mathrm{kG}$. All "peculiar" places correspond to positions with the highest intensity in the spectral continuum, and the magnetic field strength is here in the range of 3.0-5.7 kG. Notice, such strong magnetic fields were firstly discovered outside the sunspot umbra. The orientation of the magnetic field vector in "peculiar" places is close to the transversal, which is also atypical for "typical" regions and can reflect strong twisting of field lines.
\end{abstract}

Keywords: Sun, solar activity, sunspots, solar flares, magnetic fields, spectral lines, the Zeeman effect, superstrong magnetic fields.

АБСТРАКТ. У цьому дослідженні ми представлясмо старі й нові спостережні дані, що стосуються проблеми екстремально сильних магнітних полів ( $\geq 5$ кГс) в атмосфері Сонця. Ми наголошуємо, що верхня межа напруженості магнітного поля в атмосфері Сонця $є$ на сьогодні невідомою. Северний (1957) припускав еврестично, що магнітні поля у сонячних плямах можуть досягати 50 кГс. Щодо спостережних даних, то можна вказати принаймні три аргументи на користь магнітних полів рівня $\leq 10^{4}$ Гс: (1) залежність виміряного магнітного поля від фактора $g_{\text {eff }} \lambda^{2}$ магніточутливих ліній (Gopasyuk et al., 1973; Lozitsky, 1980), (2) локальні екстремуми розщеплення бісекторів у профілях $I \pm V$ для ліній з різними факторами Ланде (Lozitsky, 1980; 2015) і (3) достовірне розщеплення емісійних піків в лініях Fe I з дуже низькими факторами Ланде, близько 0.01, у спектрах потужних сонячних спалахів (Lozitsky, 1993; 1998). Теоретично, надсильні поля повинні мати гігантський магнітний тиск і можуть існувати лише при специфічній топології силових ліній, очевидно, безсилового типу (Soloviev and Lozitsky, 1986). Для подальшої розробки цієї проблеми ми аналізуємо нові спостережні дані, отримані на спектрополяриметрі NIRIS найбільшого на сьогодні сонячного телескопа GST обсерваторії Біг Бер (BBSO). Наші спостереження стосуються активної області NOAA 12673, яка була найбільш спалаховопродуктивною у 24-му циклі. Стокс-метричні вимірювання виконані в лінії FeI $15648.5 \AA$ при відношенні сигнал/шум близько $10^{-4}$. Саме в цій області були недавно виявлені магнітні поля 3 напруженістю 5.57 кГс (Wand et al., 2018). Додаткове дослідження приблизно 70 різних місць цієї активної області показало, що в ній існували ділянки двох типів, які умовно можна назвати «типовими» i «специфічними». В «типових» ділянках величина магнітного поля в цілому тим більша, чим менша інтенсивність в континуумі, причому максимальне поле тут не перевищує 4 кГс. Всі «специфічні» 
ділянки відповідали місцям 3 найбільшою інтенсивністю у спектральному континуумі, причому напруженість магнітного поля тут в межах 3.0-5.7 кГс. Слід зауважити, що такі сильні магнітні поля були вперше виявлені за межами тіней сонячних плям. Орієнтація вектора магнітного поля в «специфічних» ділянках близька до трансверсальної, що також нетипово для «типових» ділянок і може вказувати на сильне скручування силових ліній.

Ключові слова: Сонце, сонячна активність, сонячні плями, сонячні спалахи, магнітні поля, спектральні лінії, ефект Зеємана, надсильні магнітні поля.

\section{Introduction}

The upper limit of the magnetic field strength in the solar atmosphere is unknown at present. The predominant point of view is that the strongest fields can be found in the darkest parts of the umbra of largest sunspots. According to observations, the field strength in the umbra is, on average, 2100-2900 G, reaching at times 35004000 G (Solanki, 2003; Lozitska, 2010). Earliest measurements by Baranovsky and Petrova (1957), and Steshenko (1968) showed that the field strength in sunspot may reach $4900 \mathrm{G}$ and $5350 \mathrm{G}$, respectively. The record field of $6100 \mathrm{G}$ in a sunspot umbra was reported by Livingston et al (2006).

As far as sunspot penumbra is concerned, Van Noort et al. (2013) found very strong fields $(B=7-7.5 \mathrm{kG})$ in places with significant plasma downflows of $20 \mathrm{~km} / \mathrm{s}$.

We note that while Livingston et al. (2006) directly measured Zeeman splitting in various spectral lines with large Lande factors, Van Noort et al. (2013) analyzed full Stokes vector spectropolarimetry using an indirect Fourier technique to probe smallest spatial scales. It is also worth noting that when magnetic fields reach $7-8 \mathrm{kG}$ and the Doppler velocities reach $20 \mathrm{~km} / \mathrm{s}$, the Fe I 6301.5 and $6302.5 \AA$ lines used in Van Noort et al. (2013) should be considered as mutually blended. This, of course, complicates diagnostics of very strong fields ( Lozitsky, 2016).

Perhaps, extremely strong magnetic fields can exist in spatially unresolved structures with very small filling factor $f(f<<1)$. In this case, they may manifest themselves as a very weak Zeeman effects in the spectrum. Lozitsky (2016, 2017) found evidence of presence of $8-\mathrm{kG}$ fields in the sunspot umbra. The filling factor there is thought to be $0.2-$ 0.3 here, and relative Doppler velocities associated with upflowing plasma (excluding Evershed's flows) range from -1.7 to $-3.1 \mathrm{~km} / \mathrm{s}$.

Solar flares are interesting and violent processes in solar active regions where the strongest fields could exist as well. Each flare is a grandiose explosion occurring in a wide range of heights in the solar atmosphere, with a sharp increase in temperature, gas pressure and ionization of plasma. Hot pressurized flaring plasma outside magnetic flux tubes may press on walls of these tubes thus increasing magnetic strength inside the tubes. In addition, increased of plasma ionization leads to amplification of electric currents and to magnetic field intensification, if the structure of underlying magnetic field is force-free.
There were suggestions that magnetic fields with strength of tens of kilogauss may also exist on the Sun. Thus, Severny (1957) supposed the $50 \mathrm{kG}$ fields in smallscale spatially unresolved magnetic elements of sunspots, which are averaged out when they are measured with insufficient spatial resolution.

Bruce (1966) suggested that during a flare extended wings of $\mathrm{H} \alpha$ line ( till $8 \AA$ ) could intensify due to Zeeman effect in 10-100 kG fields. Really, this is one of possible interpretation: a some account to the line-profile broadening should give also temperature, turbulent velocity and electric fields. For these effects separation, the full Stokes parameters $I, Q, U$ and $V$ of polarized light are needed. On the other hand, if the magnetic field is tangled at sub-telescopical scales (for instance, in a form of mixed polarity structures) the Stokes diagnostics can not be applied since we can have essential broadening of Stokes $I$ profile but practically zero polarization at various distances from line center.

With the advances in solar instrumentation there is renewed interest in superstrong magnetic fields on the Sun as evidence by the most recent publications (Wang et al., 2018, Takenori et al., 2017).

The objective of our work is twofold, namely, we would like to review previous studies devoted to the problem of superstrong field, as well as to present new relevant results. Here we present main arguments in favor of the existence of especially strong magnetic fields.

\section{First Argument: Dependence of Measurements on the $g \lambda^{2}$ Factor}

In 1973, an important observational result was obtained, which may be considered as an indirect indication of the existence of extremely strong magnetic fields outside sunspots and flares. Gopasyuk et al. (1973) found an unexpected dependence of relative observed field $R_{\mathrm{i}}=B_{\|}\left(\lambda_{\mathrm{i}}\right) / B_{\|}(6103)$ on magnetic sensitivity factor $g \lambda^{2}$ using magnetographic data obtained in 13 spectral lines $\lambda_{\mathrm{i}}$ (Fig. 1). The data were obtained with the solar magnetograph of Crimea Astrophysical observatory. Longitudinal magnetic fields, $B \|$, were measured in range $\left|B_{\|}\right| \leq 100-200 \mathrm{G}$ using Stokes $V$ parameter. In this field range, the weak field approximation is applicable, when $B_{\|} \sim V / g \lambda^{2}$. Due to this reason, measured fields should not be dependent on $g \lambda^{2}$ factor, assuming that the solar magnetic fields are really weak. Contrary to the above reasoning, a remarkable dependence was found: $R_{\mathrm{i}}$ values were nearly the same for the lines with high magnetic sensitivity, while these values display a rapid grown for the lines with decreasing $g \lambda^{2}$ factor.

Similar dependence was also observed by Lozitsky (1978) using Stokes $I$ data recorded by the Crimea spectrograph in areas of two weak solar flares, where the measured magnetic field was stronger, $\leq 1000 \mathrm{G}$ (triangles in Fig. 1). The magnetic field were estimated by observed Stokes $I$ intensity gradient, $\mathrm{dr}_{\lambda} / \mathrm{d} \lambda$, measured for about ten Fe I lines and compared with theoretical expectations derived from Unno (1956) theory. One can see from Fig. 1 that Stokes $V$ and $I$ measurements are in excellent agreement, which seemingly rules out the instrumental nature of the above mentioned effects and suggests that it has an solar origin. 


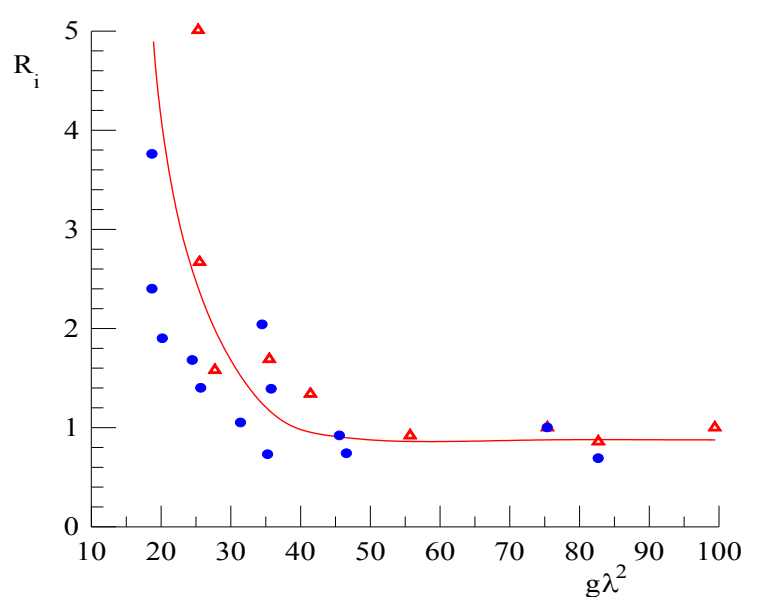

Figure 1: Observed dependence of the relative observed field $R_{\mathrm{i}}=B_{\|}\left(\lambda_{\mathrm{i}}\right) / B_{\|}(6103)$ on the magnetic sensitivity factor $g \lambda^{2}$ as derived from Stokes $V$ (filled dots) and Stokes $I$ (triangles) parameters.

Lozitsky (1980) further showed that such dependence may arise in case that the underlying magnetic field is two-component consisting of a relatively weak background field and spatially unresolved magnetic elements with strong fields of order of $8-10 \mathrm{kG}$, depending on the spectral line half-width and Doppler velocities present in these assumed sub-telescopic structures. In this case, the filling factor, $f$, of such structures should be proportional to magnitude of the background field $B_{\text {back }}$.

\section{Second Argument: Local Extrema in the Splitting of Bisectors}

Lozitsky (1980) reported another deviation from the weak field approximation found for sub-kilogauss, $\leq 600 \mathrm{G}$, non-sunspot magnetic fields. The observed data were obtained with the Echelle spectrograph installed on the Horizontal Solar Telescope (HST) of the Astronomical Observatory of Taras Shevchenko National University of Kyiv (Lozitsky, 2016). It was found that the measured splitting, $\left(\Delta \lambda_{\mathrm{H}}\right)_{\mathrm{obs}}$, of $I \pm V$ profiles changes with the distance, $\Delta \lambda$, from the center of spectral lines with a small Lande factors $\left(g_{\text {eff }}=1-1.3\right)$ and a considerable half-widths ( $\Delta \lambda_{1 / 2}=0.2-0.3 \AA$ ). While some of the analyzed spectral lines exhibited an increase in the magnitude of splitting, other showed a decrease or even a non-monotonic dependence. To reduce influence of possible errors, the measurements were averaged over a solar region of about 36 arc sec length.

In weak-field approximation the value of $\left(\Delta \lambda_{\mathrm{H}}\right)_{\text {obs }}$ (or splitting of bisectors, $B S$, of $I \pm V$ profiles) should be the same at all distances, $\Delta \lambda$, from the line center, while observations showed to the contrary.

In Fig. 2 we plot $B S$ as a function of $\Delta \lambda / g \lambda^{2}$, which shows three distinct maxima. The reason for this is easy to understand, if we recall that the Zeeman splitting $\Delta \lambda_{\mathrm{H}}$ is

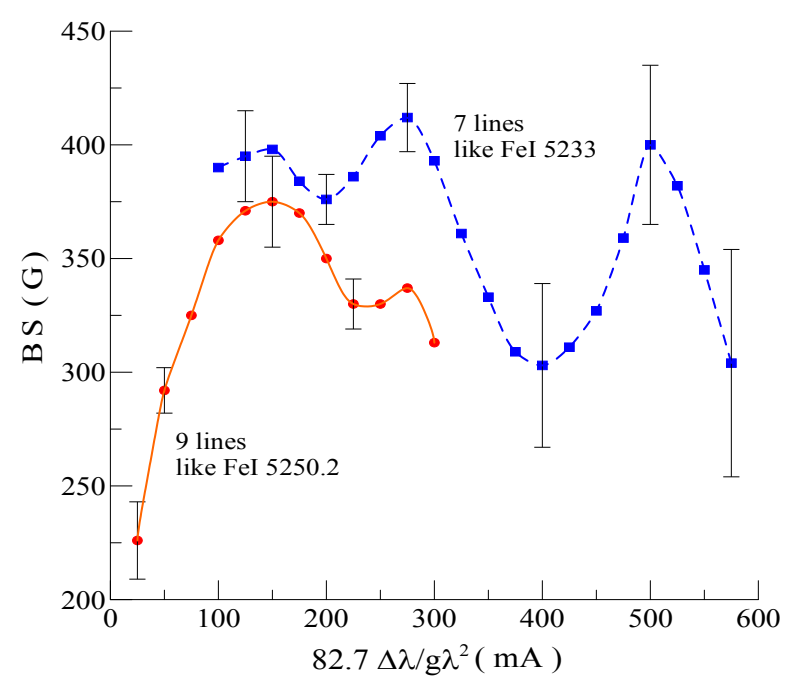

Figure 2: Averaged bisector splitting $B S$ vs. the normalized distance from the line center, 82.7 $\Delta \lambda / g \lambda^{2}$, plotted for 9 narrow lines such as FeI 5250.2 (filled circles and solid line) and for 7 lines such as FeI 5233 (squares and stroke line). The Landé factors of these lines ranges from 1.0 to 3.0. The mean-square errors of measurements are indicated with the vertical intervals. (Lozitsky, 2015).

proportional to the product $g \lambda^{2} B$, where $B$ is the magnetic field strength. Thus, when we take the ratio $\Delta \lambda / g \lambda^{2}$ for any maximum in Fig. 2, we in fact fix the magnitude $B$ of the magnetic field because $B \sim \Delta \lambda_{\mathrm{H}} / g \lambda^{2}$.

One can see from Fig. 2 that although the narrow spectral lines such as FeI 5250.2 and wider lines such as FeI 5233 exhibit certain discrepancy between the absolute values of the measured $B S$, the position of the maximums

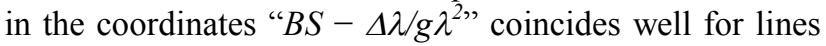
of both types and corresponds to fields strength of 3-4, 78 and $\approx 13 \mathrm{kG}$. This leads to an interesting conclusion that the intensity of the magnetic field in spatially unresolved structures may not only reach $10^{4} \mathrm{G}$, but it may also acquire discrete values. It was latter shown that theoretical interpretation of such superstrong and "quantized" magnetic fields is possible within the framework of a linear force-free model (Soloviev and Lozitsky, 1986). This model is described by Bessel's functions $J_{0}$ and $J_{1}$ of zero and first orders and has a multipolar periphery and the magnetic field up to $\sim 10^{4} \mathrm{G}$ with discrete values near the tube axis. For a $10^{4} \mathrm{G}$ field, a large number of discrete layers with opposite magnetic polarity is required to be present inside one small-scale structure.

Similar results were later obtained for solar flares as well (Lozitsky, 2015) and they are shown in Fig. 3. Here, the magnitude of splitting of bisectors of $I \pm V$ profiles is shown at different distances from the center of Fe I $5233 \AA$ spectral line averaged over a number of solar flares, ranging from 3 to 12. The dots and solid lines represent observed flare data, and the dashed lines show the noise level in each case. Since both emission and absorption spectral contributions of strong fields are possible during flares, as well as contributions from different magnetic polarities, the SDFLT values in Fig. 3 show the averaged standard deviation of the observed bisector splitting from the linear trend (regardless of the sign) on dependence " $B S-\Delta \lambda$ ”. 


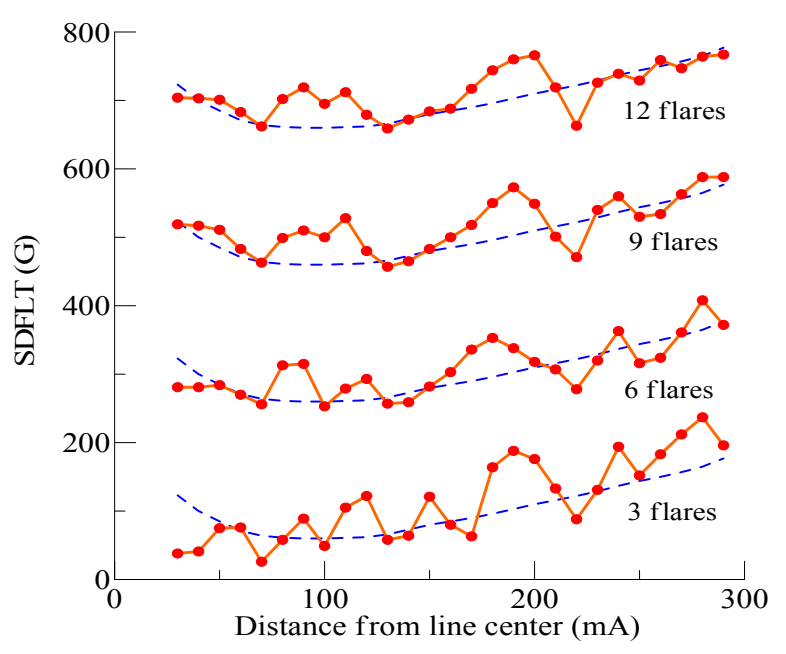

Figure 3: Averaged standard deviation of observed bisector splitting observed during flares from the linear trend (SDFLT) calculated for Fe I $5233 \AA$ Á line. Dependencies for 6,9 and 12 flares are shifted along the y-axis by 200, 400 and $600 \mathrm{G}$, respectively, for the sake of clarity. The dashed lines denote the expected error level.

It can be seen that when averaging over the maximum number of flares, two distinct peaks appear at 80-100 and 170-200 m $\AA$ from the center. If we interpret this effect as an evidence of presence of weak Zeeman sigma components associated with spatially unresolved magnetic structures, then the corresponding magnetic field strengths will approximately be 6 and $12 \mathrm{kG}$, i.e. close to the $7-8$ and $\approx 13 \mathrm{kG}$, estimates obtained earlier for non-flare regions.

It is interesting to note that similar conclusions were made by Ulrich et al. (2009) using Fe I 5233 line measured in quiet Sun regions. They observed only one maximum at $80 \mathrm{~m} \AA$ (see Fig. 7 in Ulrich et al., 2009)). It is possible, the absence of the second maximum at 170$200 \mathrm{~m} \hat{A}$ in case of quiet regions reflects a simpler magnetic field structure, as compared to a flaring active region, with fewer types (modes) of flux tubes with different magnetic intensities.

According to simulations (Lozitskii, 1986), the above interpretation of data shown in Figs. 2 and 3 is applicable only if the real half-widths of the spectral lines measured in locations of very strong fields are much smaller than those usually observed in quiet Sun regions. For example, for Fe I 5233 line it is necessary to assume that its width in places with an extremely strong field is reduced by approximately 6-7 times - from $300 \mathrm{~m} \AA \hat{~}$ to $40-50 \mathrm{~m} \AA$. However, we will show later, that the width reduction occurs at least in places of bright emission of solar flares.

\section{Third Argument: Splitting of Emissive Peaks in Lines with Lande Factors about 0.01}

Lozitsky (1993, 1998) presented the most direct evidence for existence of superstrong magnetic fields in solar flares inferred from data collected using FeI lines with very low Lande factors (Lozitsky, 1993, 1998). The data were obtained with HST Echelle spectrograph. It was found

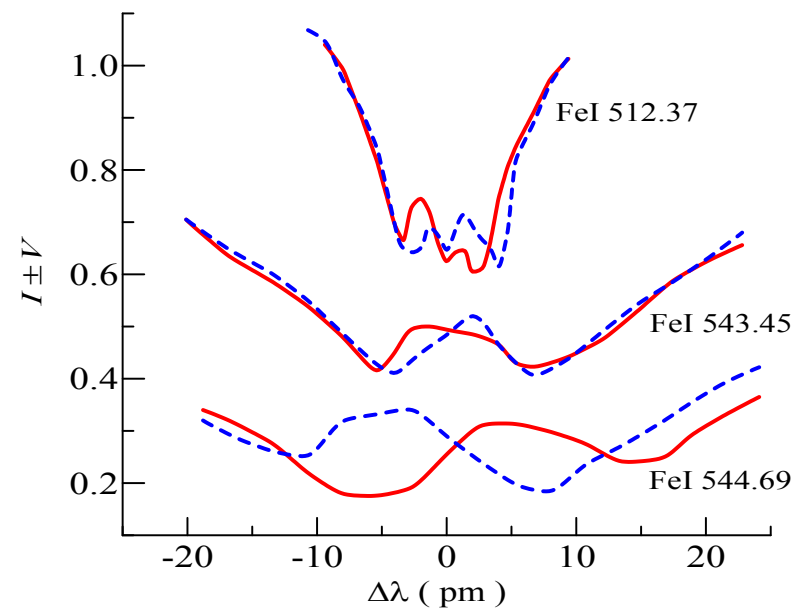

Figure 4: Comparison of $I \pm V$ profiles of FeI 5123.7, FeI 5434.5 and FeI 5446.9 lines observed during a solar flare on 16 June 1989 (Lozitsky, 1998; 2003). Their empirically determined Lande factors are $-0.013,-0.014$ and 1.249, respectively. One can see not only a significant splitting of the emission peaks in the first two lines, but also that the sign of this splitting (i.e., the sign of the Stokes $V$ parameter ) is opposite to the sign of similar effect in the third line, which has positive Lande factor.

that Stokes $I \pm V$ profiles of some spectral lines, such as FeI ${ }^{5} \mathrm{~F}_{1}{ }^{5} \mathrm{~F}_{1} \lambda=5123.723 \AA$ and FeI ${ }^{5} \mathrm{~F}_{1}{ }^{5} \mathrm{D}_{0} \lambda=5434.527 \AA$, exhibit narrow and splitted emission peaks in their cores during flares. Both these lines have a zero theoretical Lande factors for $L S$ coupling, however, their laboratory determined Lande factors, $\mathrm{g}_{\mathrm{Lab}}$, are exceptionally small, non-zero, $\mathrm{g}_{\mathrm{Lab}}=-0.013$ and -0.014 , respectively (Landi Degl'Innocenti, 1982).

The observed splitting of emission peaks in $I \pm V$ profiles was measured to be $\Delta \lambda_{V}=10-36 \mathrm{~m} \AA$, whereas the splitting in $I \pm Q$ profiles was close to zero $\left(\Delta \lambda_{Q} \leq 5 \mathrm{~m} \AA\right)$. Taking into account that the non-flaring profiles did not display similar effects, it was assumed to be manifestation of the Zeeman effect in a field of $B \approx 26-94 \mathrm{kG}$.

According to the data, other significant features of superstrong magnetic fields in flares are as follows. The maximum value of the superstrong field (about $90 \mathrm{kG}$ ) was observed in the maximum phase of the flare, similar to the peak of kilo-gauss fields (1.1-1.5 kG) according to FeI 5247.1 and 5250.2 data which was observed also in peak of a flare and not in its flash phase (Lozitska and Lozitsky, 1994).

The observed width of the flare emission in FeI 5123.7 and 5434.5 lines reached $30 \mathrm{~m} \AA$ suggesting that the actual width should only be $10-20 \mathrm{~m} \AA$ after the instrumental profile of the spectrograph is taken into account (Lozitsky et al., 1999). As can be seen from Fig. 4, the magnetic field inferred from a spectral line with Lande factor of 1.25 was about $3 \mathrm{kG}$ while the lines with Lande factor of 0.01 produced estimates close to $90 \mathrm{kG}$. This means that the underlying magnetic field structure was multicomponent and included both $10^{3} \mathrm{G}$ and $10^{4} \mathrm{G}$ fields.

To date, manifestation of superstrong magnetic fields have been detected in five powerful solar flares. However, it is not yet known whether these superstrong fields are 
the prerogative of only powerful flares, or they may exist in other solar structures but their spectral manifestation is too weak to be detected with modern instrumentation.

\section{New Observational Data}

We studied in detail magnetic fields in an active region NOAA 12673, which was the most flare productive active region (AR) in the solar cycle No. 24. It produced four Xclass flares including the X9.3 flare on 2017 September 06 and the X8.2 limb event on September 10. Wang et al (2018) detected extremely strong magnetic fields of 5.57 $\mathrm{kG}$ in this $\mathrm{AR}$, which is about $1300 \mathrm{G}$ above what Zirin and Wang (1993) found in flare productive sunspots.

Observations were carried out with the Goode Solar Telescope of Big Bear Solar Observatory (Cao et al., 2010). The GST is the first of a new generation of large aperture solar telescopes that will culminate in the ATST and the EST with 4-m apertures. This telescope has an adaptive optics system and can reach the diffraction limit of angular resolution which is equal of $0.06 "$ at $500 \mathrm{~nm}$ and $0.2^{\prime \prime}$ at $1565 \mathrm{~nm}$.

Stokes $\{I, Q, U, V\}$ profiles of FeI $15648.5 \AA$ line $\left(g_{\text {eff }}=\right.$ 3.0) were obtained with the Near-InfraRed Imaging Spectro-polarimeter (NIRIS) on 6 September 2017, when the AR was located at angular distance of $34 \mathrm{deg}$ from the disk center. This instrument has spectral resolution about $0.1 \AA$ and signal-to-noise ratio about $10^{-4}$. Spectral line FeI 15648.5 forms about 200-300 km deeper than wellknown visible lines FeI 5250.2, 5247.1, 6301.5 and $6302.5 \AA$ (Khomenko and Collados, 2007) and one can expect that FeI 15648.5 line measurements represent such levels in atmosphere where magnetic fields can be particularly strong.

In comparison with the previously published findings of Wang et al. (2018), we probed the magnetic field at about 70 locations in the AR, which include a large number of anomalous Stokes profiles originating in a nonuniform magnetic field. In this study, we focus our attention only on the most simple effects that can be interpreted within the framework of the transfer theory in a homogeneous magnetic field.

Due to the high magnetic sensitivity of the FeI 15648.5 line and its relatively small spectral range, complete separation of the Zeeman $\pi$ and $\sigma$ components could be observed only when the magnetic field exceeds $1500 \mathrm{G}$. In this case, the modulus of the magnetic field strength is measured, rather than its longitudinal component, as it is customary for magnetographic measurements. In most cases, full component separation was most clearly recorded in Stokes $U$ profile, that is, in linear polarizations (Fig. 5).

Comparison of the measured field strength to the continuum intensity near FeI $15648.5 \AA$ line showed an important feature, namely, i.e., in the "magnetic field versus continuum intensity" diagram (Fig. 6), all measurements are divided into two clusters: consisting of typical and unusual dependencies.

For typical dependencies, a well-known relationship between the magnetic field and intensity is observed, when the greater the magnitude of the magnetic field is, the lower the corresponding intensity in the continuum. The magnetic

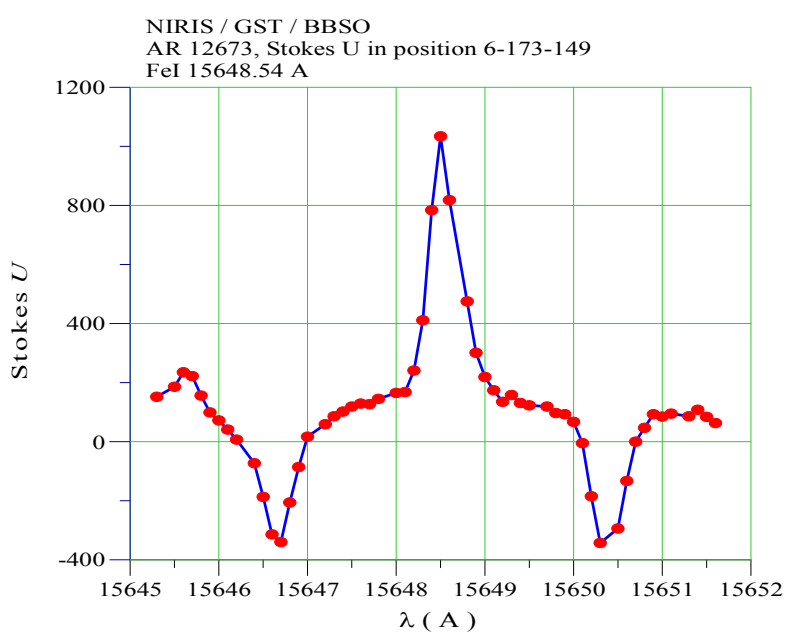

Figure 5: Stokes $U$ of FeI 15648.5 line observed with NIRIS in position \# 6 in AR 12673 which corresponds to a light bridge between two umbra of a sunspot. Spectral distance between $\sigma$ components is equal here $3.7 \AA\left(\Delta \lambda_{\mathrm{H}}\right.$ $=1.85 \AA$ ) which corresponds to magnetic field of $5.4 \mathrm{kG}$.

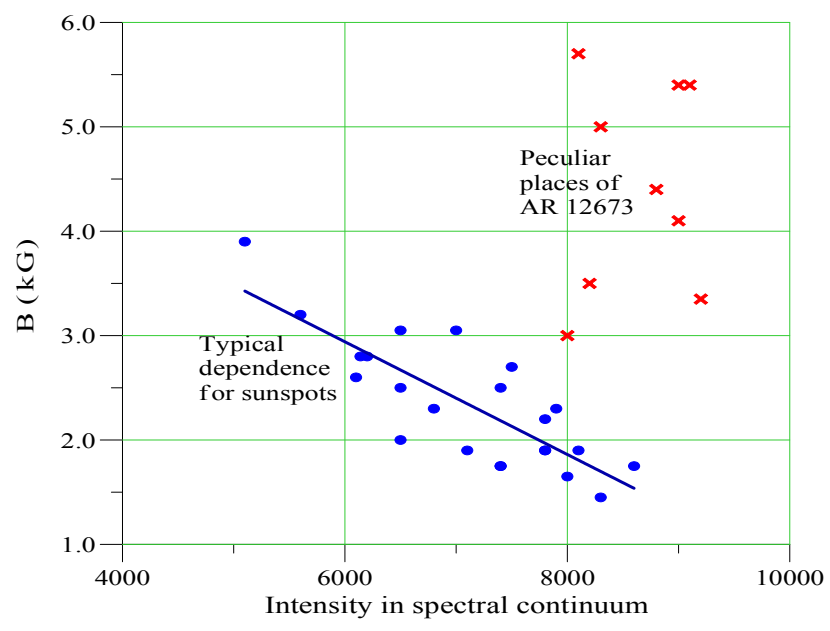

Figure 6: Measured magnetic field $B$ in AR 12673 versus intensity in spectral continuum. One can see that all places in this AR can be divided on two types: "typical" and "peculiar" (see the text).

field here ranges from 1.5 to $3.9 \mathrm{kG}$, and it may be linearly approximated with decreasing intensity in the continuum. All the unusual locations displayed the highest continuum intensity, and the magnetic field there was found to be between 3.0 and $5.7 \mathrm{kG}$.

As far as we know, this situation is marked for the first time. Usually the strongest magnetic fields are localized in the dark umbra of sunspots, and not in bright areas outside these spots.

It is well known that the orientation of the magnetic field vector in the center of sunspot umbra is close to radial, i.e. it coincides with the vertical direction at a given location of the solar surface. It is therefore interesting to determine the orientation of the magnetic vector in these peculiar regions. In view of the large number of anomalous Stokes profiles that have been observed, more 


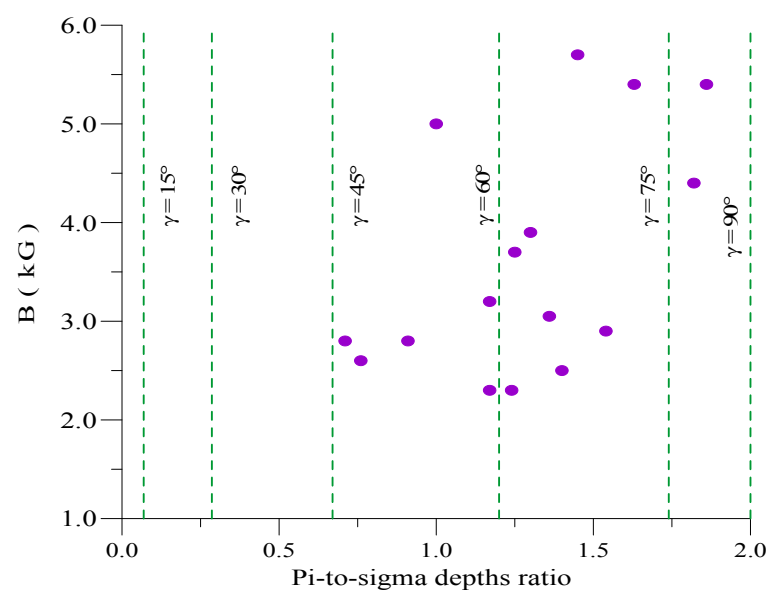

Figure 7: Estimates of the directional angle $\gamma$ between the magnetic field vector and the line of sight derived from formula (2). Vertical dashed lines show the calculated ratio of the depths of of $\pi$ and $\sigma$ components corresponding to a certain angle of inclination of the field.

reliable determinations of the orientation of the vector $\boldsymbol{B}$ can apparently be made along the profiles of the integral intensity, $I$. The FeI $15648.5 \AA$ line is rather weak, and its central depth outside spots is about 0.3 . In this case, the approximation of an optically thin line is applicable, which makes it possible to use the Seares (1913) formula

$$
d_{\pi} / d_{\sigma}=0.5 \sin ^{2} \gamma / 0.25\left(1+\cos ^{2} \gamma\right) \text {, }
$$

where $d_{\pi}$ and $d_{\sigma}$ are depths of $\pi$ and $\sigma$ components, respectively, and $\gamma$ is an directional angle between the magnetic field vector and the line of sight. If we denote $d_{\pi} / d_{\sigma}=k$, then, we obtain that

$$
\cos \gamma=\{(1-k / 2) /(1+k / 2)\}^{1 / 2} .
$$

The directional angle, $\gamma$, determined according to formula (2) are shown in Fig. 7. This includes only those cases where the $\pi$ and $\sigma$ components are completely spectrally separated and do not affect the depth of the neighboring component of the Zeeman splitting.

Figure 7 shows an interesting feature: all locations with strongest fields in the given AR exhibit the greatest directional angles, $\gamma$. In particular, three cases with $B=$ $5.4-5.7 \mathrm{kG}$ correspond to $67^{\circ}<\gamma<79^{\circ}$.

The heliocentric angle, $\theta$, of the AR was approximately 34 degrees. In this case, depending on the orientation of the field vector in the picture plane, the angles of the lines of force with respect to the vertical should be from $\gamma-\theta$ to $\gamma$ $+\theta$.. Based on the data in Figure 7, we find that the actual angles to the vertical direction were between 33-45 degrees and 101-113 degrees.

The large direction angle possibly indicates the extremely strong fields there were nearly horizontal, and not vertical, as in the sunspot umbra. A direct comparison of the obtained measurements of the magnetic field with heliograms in the molecular $\mathrm{TiO}$ line showed that all the strongest fields were localized in the bright bridges between the sunspot umbra.

\section{Discussion and Conclusion}

The Fe I $15648.5 \AA$ line is attractive for measurements not only because it gives the magnetic field module at fields above $1.5 \mathrm{kG}$, but also because due to its high magnetic sensitivity it allows estimating the dispersion of the field strengths in magnetic elements. Really, Botygina et al. (2016) found that in quiet Sun regions outside sunspots the diameter of the smallest flux tubes is about $15-20 \mathrm{~km}$. The spatial resolution of the GST NIRIS data is about $150 \mathrm{~km}$, that is an order of magnitude less than required to resolve such elementary structures. Thus, it is likely that there is a hidden complex structure within the sampling pixel of NIRIS instrument. If the magnetic fields would significantly differ in intensity, we would observe diffuse $\sigma$ components in the Zeeman effect. However, the observed blurring of these components, at all is negligible since the observed half-width is about $0.5 \AA$ (Fig. 5), while the observed line width in quiet Sun region is much smaller and is about $0.3 \AA$. This indicates that the dispersion of the field intensity in neighboring sub-telescopic flux tubes comparison a single NIRIS pixel, is generally negligible.

Let us summarize our findings. The modulus of the magnetic field vector was measured in several locations across AR NOAA 12673 - the most flare-producing sunspot group in the 24 th cycle of solar activity. Unlike earlier studies that involved magnetographic measurements and inversion methods our measurements are the most direct and therefore reliable.

We report that a case when extremely strong magnetic fields in the range 5.0-5.7 kG were concentrated not in the dark nuclei of sunspot, but in bright areas of an AR.

Comparison of approximately 70 data points associated with various magnetic structures in the AR showed that there were two types of profiles. In typical areas, the magnetic field was within 1.5-3.9 $\mathrm{kG}$ and the more intense fields were associated with lower continuum intensity. In other, unusual locations, the intensity of the magnetic field was ranging from 3.0 to $5.7 \mathrm{kG}$, all of them were associated with nearly the same underlying continuum intensity. The orientation of the field vector in those unusual locations was determined to be close to transverse, which may indicate a strong twist of magnetic structures.

Acknowledgements. VYu acknowledges support from AFOSR FA9550-15-1-0322 and NSF AST-1614457 grants. BBSO operation is supported by NJIT and US NSF AGS-1821294. GST operation is partly supported by the Korea Astronomy and Space Science Institute (KASI), Seoul National University, and by strategic priority research program of CAS with Grant No. XDB09000000. This study was funded by Kyiv Taras Shevchenko National University project No. 16БФ023-01.

\section{References}

Baranovsky E.A., Petrova N.N.: 1957, Solnechnyje Dannyje, № 5, 118 .

Botygina O.O., Gordovskyy M.Yu., Lozitsky V.G.: 2016, Adv. Astron. Space Phys., 6, 20.

Bruce C.E.R.: 1966, Observatory, 86, 82. 
Cao W., Gorceix N., Coulter R. et al.: 2010, Astron. Nachr., 331, 620.

Gopasyuk S.I., Kotov V.A., Severny A.B. et al.: 1973, Solar Phys., 31, 307.

Khomenko E., Collados M.: 2007, The Astrophys. J., 659, 1726.

Landi Degl'Innocenti E.L.: 1982, Solar Phys., 77, 285.

Livingston, W., Harvey, J.W., Malanushenko O.V.: 2006, Solar Phys., 239, 41.

Lozitska N., Lozitsky V.: 1994, Solar Phys.,151, 319.

Lozitska N.I.: 2010, Kosm. Nauka i Tekhnologia, 16, 30.

Lozitskii V.G.: 1986, Kinem. Fiz. Neb. Tel, 2, 28.

Lozitsky V.G., Lozitska N.I., Gordovskyy M.Yu.: 1999, Bull. Taras Shevch. Nat. Univ. of Kyiv. Astronomy, 35, 17.

Lozitsky V.G.: 1978, Solnechnyje Dannyje, № 8, 74.

Lozitsky V.G.: 1980. Physica Solariterr., Potsdam. 14, 88.

Lozitsky V.G.: 1993, Kinem. Phys. Celest. Bodies, 9, 18.

Lozitsky V.G.: 1998, Kinem. Phys. Celest. Bodies, 14, 401.

Lozitsky V.G.: 2003, DrSci Thesis, Kiev, 299p.
Lozitsky V.G.: 2015, Adv. Space Res., 55, 958.

Lozitsky V.G.: 2016, Adv. Space Res. 57, 398.

Lozitsky V.G.: 2017, Adv. Space Res. 59, 1416.

Seares F.H.: 1913, Astrophys. J. 38, 99.

Severny A.B.: 1957, Astron. Zhurnal, 34, 684.

Solanki S.: 2003, The Astron. Astrophys. Rev., 11, 153.

Soloviev A.A., Lozitsky V.G.: 1986, Kinematika i Fizika Nebesn. Tel, 2, 80.

Steshenko N.V.: 1967, Bull. Crimea Astrophys. Obs., 37, 21.

Takenori Okamoto, Takashi Sakurai: 2017, arXiv: 1712.08700v1[astro-ph.SR] 23 Dec 2017.

Ulrich, R.K., Bertello, L., Boyden, J.E. et al.: 2009, Solar Phys. 255, 53.

Unno W.: 1956, Publs. Astron. Soc. Japan, 8, 108.

Van Noort M., Lagg A., Tiwari S.K. et al.: 2013, Astron. Astrophys. 557, id.A24, 14 pp.

Wang Y., Yurchyshyn V., Lin C. et al.: 2018, Res. Notes of the American Astron. Society, 2, No. 1. 